\title{
REVIEW OF SURVEY METHODS IN EVENTS MANAGEMENT RESEARCH
}

\author{
RICHARD FLETCHER* AND JAMES BOSTOCK $\dagger$ \\ *Arts \& Festivals Management, De Montfort University, Leicester, UK \\ $\uparrow$ Sport Management, University of Derby, Derby, UK
}

\begin{abstract}
Questionnaire-based surveys are a common data collection tool in events research as established by earlier reviews of methods within the literature. This article examines and critiques the historic development, current position, gaps in knowledge, and future implications for survey-based research. Two-hundred eighty-six articles from four events-specific journals were reviewed. Some diversity is found within survey-based research; however, the majority was carried out: as a single method (86\%), in physical proximity to the event $(67 \%)$, during the event $(49 \%)$, using paper-based forms $(65 \%)$, designed for self-completion $(94 \%)$. The most common events targeted were: sports $(43 \%)$ festivals \& celebrations (20\%), and music (12\%). The stakeholders targeted were: audiences (54\%), nonparticipants $(16 \%)$, and managers $(12 \%)$. Sampling methods, where stated, were likely to be random $(23 \%)$ or convenience based (22\%). Despite the predominance of this data collection tool, numerous areas are ideally in need of further understanding and experimentation. Mixed methods, multiple surveys, and more deliberate approaches to sampling are required. Despite an audience focus, "before and after" studies are lacking. Electronic surveys and other emerging technologies undoubtedly provide options but these do not appear to have been investigated or adopted with sufficient rigor. Targeting stakeholders other than audiences, covering a broader range of events, and longitudinal studies would also be desirable. The use of survey-based research by policy makers and funders is discussed as it potentially orients towards what the authors term "operationalized knowledge management." A brief but comprehensive typology of survey methods is established to aid future researchers.
\end{abstract}

Key words: Survey; Research methods; Questionnaire; Audience research; Knowledge management

Introduction

Questionnaire-based surveys are a familiar and arguably fundamental tool for events and festivals researchers, being frequently deployed among various stakeholders; audiences, residents, managers, and participants. Considering the classic definition of festivals as events that express the historic continuity of a defined community (Falassi, 1987), it follows that practitioners and academics 
wish to develop understanding of these communities. Identifying the prevalence of survey-based methods in the social sciences, leisure, and tourism or events research is not, in itself, original. Therefore, this article investigates trends, methodological gaps, and technological developments in survey research, providing a critical perspective on this ubiquitous data collection tool. A previous review found that $92 \%$ of events research articles from 1997-2000 used survey methods, which reduced to $64 \%$ by $2010-2013$. However, due to the growth of the literature as a whole, this still showed an absolute increase from 13 survey-using articles to 65 (Crowther, Bostock, \& Perry, 2015). This article builds from the review of Crowther et al. to further understand the variations of survey usage and to interrogate the influence this may have on methodological choices and policy outlook.

Research and evaluation of any sort are typically thought to provide insight and competitive advantage in the short term while the articulation of impact and legacy can provide a lasting resource for event organizations. The temporary, "pulsating" nature of many events organizations suggests they often struggle to become "learning organizations" (Getz \& Page, 2016, p. 350). As festivals age their propensity to undertake some kind of formal evaluation increases, though themes and methods of investigation vary (Robertson, Rogers, \& Leask, 2009). Many festival-producing organizations are notfor-profit, volunteer managed, externally funded, and highly scrutinized by the public (Getz, 2002). One "future proposition" for Event Studies is that public-sector investment, especially in mega-events, will be increasingly difficult to defend; although at the same time, social, cultural, and environmental justifications may become more acceptable (Getz \& Page, 2016, p. 431). Visitor experience, motivation, satisfaction, and intentions are increasing topics of interest (Park \& Park, 2016).

Although surveys in the abstract are not a precept of research or evaluation, they have clearly played an important role: "Any research method can be useful. . . . No doubt visitor surveys are a predominant research tool in evaluating everything from satisfaction to economic impacts" (Brown, Getz, Petterson, \& Wallstam, 2015, p. 150). Evaluation theory is further advanced in the recent textbook Event Evaluation (Getz, 2018). In particular,
Chapter 10: "Evaluating visitors and experiences" helps situate the use of surveys within a comprehensive evaluation system, one that may also draw on attendance monitoring, participant observation, and experience evaluation. An earlier "Basic data needs" summary for events management covered 10 topics, of which seven are identified as suitable for survey methods (Getz, 2005, p. 382). It is likely survey methods will continue to be of interest, not least due to new technologies. Although contemporary events research textbooks naturally cover survey methods (Fox \& Gouthro, 2014; Veal \& Burton, 2014) they are comparatively light on the expanding possibilities and methodological considerations of electronic surveys and other rapidly developing innovations in data collection besides.

Technology aside, there are a range of potentially overlooked factors in events survey methodologies. Greater understanding of these would bolster the significance of individual studies and help direct future research towards more novel approaches. These overlooked factors are rooted in the well-discussed characteristics of "the event phenomenon," which Crowther et al. (2015) summarized along four lines: experientiality of attendees and other stakeholders, congregation or copresence, transient or temporal nature, and the intentionality of design or programming. To comment on the suitability of survey methods to every event context imaginable is not within the scope of this article, but with these four dimensions in mind, it is clear that surveys could have both significant strengths and weaknesses in ultimately addressing the central subject of event phenomena.

Given the intensive attention given to surveys, it is fair to say that the authors' philosophical stance is mostly positivist. However, the purpose of this research is not just to chart, but to critique survey methods. The approach of this article may be described as cautiously skeptical, drawing on aspects of critical realism (Bhaskar, 1975; Sayer, 2000). Others have highlighted the value critical realism can bring to "hybrid" fields, similar to events management, that also emphasize policy and management issues (Downward, 2005). Of course, surveys alone are not sufficient to provide ontological depth to our knowledge of events, or to explain important contextual factors.

Many have called for the increased use of qualitative and mixed methods in events research (Getz, 
2010). There is little to suggest that surveys cannot add value as part of a triangulated, mixed-method approach. Others argue that the supposed animosity between quantitative and qualitative methods can often be unhelpfully overstated (Olson, 2004). Longitudinal studies are sparse and it is likely that surveys could contribute here; a sentiment echoed within sustainable tourism (Lu \& Nepal, 2009). Familiarity and cost alone are poor justifications for the selection of any research method. Some of their perceived strengths in comparability and objectivity perform a kind of democratic abstraction, which arguably obfuscates underlying power dynamics and makes them a magnet for operationalization, as will be discussed.

For clarity, we strictly refer to questionnairebased surveys, though we recognize that the term "survey" is used interchangeably, to refer to both a singular response, as well as the aggregation and analysis of multiple responses. Similarly excluded are more singular forms (registrations, checklists, quizzes), though these potentially produce similar, aggregate data. We assume the reader can tolerate a degree of ambiguity where references to singular and multiple surveys are made.

This article will first outline the past, present, and potential future of survey-based research from a variety of fields. Secondly, the findings of a literature review of survey-based events research. Finally, discussion of the implications, particularly the growing need for information and knowledge management proficiency among events professionals.

\section{Origin and Expansion of Surveys}

Surveys as a research concept are easily found within a number of research typologies and thesauri, such as the UNESCO Thesaurus, the Humanities and Social Science Electronic Thesaurus, and the SAGE research methods map. The social science typology produced by the UK National Centre for Research Methods (NCRM) in 2004 (BeisselDurrant, 2004) and updated in 2015 (Luff, Byatt, $\&$ Martin, 2015) is useful to us at the outset. Survey and Questionnaire Design is found here as a subcategory of Data Collection, with key methods (Face-to-face, Postal, etc.) as further subcategories. Therefore, surveys are identified as having their own microlevel complexities, while being one of several possible methods of data collection, all underneath macrolevel frameworks of research design.

Marsh (1979) gave an interesting insight into, now slightly historic, criticisms of survey methods. This refutes "antiscientist" claims that surveys are intrinsically positivist and illuminates potential resolutions to what are suggested to be primarily methodological rather than epistemological concerns. Despite the "great expansion" of sociology in the 1960s, both the reduced teaching of quantitative methods and changing interests led to reduced expertise among future generations of researchers (Payne, 2014). Surveys were once a key province of cutting-edge academic sociology, but have been greatly expanded upon and adopted by the private sector and market research (Savage \& Burrows, 2007). Furthermore, in a digital age of "knowing capitalism," empirical sociology must now adapt to "big data," which claims to access social reality in previously impossible levels of detail. Development and application of these new tools are predominately in the private sector, rather than the academy (Burrows \& Savage, 2014).

Previous methodological reviews can help identify influential trends towards events studies. Events Management is found in the journal ranking of the Chartered Association of Business Schools (ABS) under Sector Studies (Tourism and Hospitality Studies was absorbed into Sector Studies in 2015). The Annals of Tourism Research (ATR) published one of the first methods reviews in 1988 (Dann, Nash, \& Pearce, 1988). This covered 441 articles, from ATR (1974-1986) and the Journal of Leisure Research (JLR) (1976-1986). This emerging sphere of research, with roots in geography and anthropology, was said to sometimes "gloss over" questions of theory and method. Studies could be: "theoretical discourse without empirical foundation, descriptive essays which assemble a collection of impressionistic and anecdotal material [or] data analyses devoid of theoretical content" (Dann et al., 1988, p. 4) The proportion of data collection methods used was as follows: official statistics $(28 \%)$, review of literature (25\%), interviews (18\%), observation (12\%), qualitative (9\%), and questionnaires (7\%). Over time, there was: "a decline in 'state of the art' literature reviews" (Dann et al., 
1988, p. 8) and: "interviews and questionnaires appear to show the most versatility with respect to variety of analytical technique" (Dann et al., 1988, p. 9) The value of meta-analysis is noted, directing researchers and journals to underserved topics and methods, taking a more systematic and cumulative approach to establishing knowledge.

A more recent review of three leading tourism journals (ATR, JLR, and Tourism Management) covered 1671 articles from 1999-2008 (Dunn \& Wickham, 2012). There has been a clear change since the $1970 \mathrm{~s}-1980 \mathrm{~s}$, as $54 \%$ of articles were purely quantitative, $19 \%$ were purely qualitative, $11 \%$ were mixed, and $16 \%$ were conceptual. Surveys were the largest subcategory within both quantitative (34\%) and mixed methods (28\%). Over time, qualitative and mixed-method approaches had increased though this was not found to be statistically significant: "the emerging tourism discipline remains skewed significantly towards positivism and a priority to describe and explain how tourism works in the "real world"" (Dunn \& Wickham, 2012, p. 14). Qualitative and mixed methods are hampered in many fields by the barriers faced in terms of limited word counts in journals to both explain methods and discuss the complexities of their findings: "The dominance of quantitative methodologies in the leading tourism journals ... is likely not representative of an active policy against qualitative research per se, or a discipline bias, but rather an artefact of the journal genre" (Dunn \& Wickham, 2012, p. 14).

The Journal of Sustainable Tourism is a comparatively younger leading journal, established in 1993. Published between 1993 and 2007, 341 articles were reviewed and the following proportions identified: $41 \%$ qualitative, $37 \%$ quantitative, $6 \%$ mixed methods, and $16 \%$ theoretical (Lu \& Nepal, 2009). Crucially, in this analysis, surveys are identified as qualitative methods while the main quantitative form is the case study. These proportions have not changed greatly over time and the authors suggest that tourism studies is still within the "prescience" stage of Kuhnian scientific knowledge. Other issues noted are the predominately Western perspectives of authors and that the content is more multidisciplinary than interdisciplinary.

That surveys have become commonly used in events research is hardly a surprise but the field is not devoid of any tension or debate on the topic. The growing fields of tourism, leisure, and events all continue in their struggle to establish and maintain coherent, influential positions. New technologies may both expand and complicate survey usage, while presenting more fundamental challenges to the underlying utility of academic social research.

\section{Paper and Electronic Surveys}

The first published research on web surveys emerged in 1996, following the release of mainstream graphic web browsers from around 1995 (Couper \& Miller, 2009). Importantly, not all electronic surveys are web surveys. In one typology, the three main types are: "point of contact," where a computer is used in a specific physical location; "e-mail," where respondents reply directly to an e-mail (or e-mail attachment); and what now may be the most common, the "web-based" survey, where respondents navigate to a specific webpage to interact with the survey instrument (Jansen, Corley, \& Jansen, 2007).

The main benefits of e-survey methods are proposed to include the elimination of data entry, advanced features (validation, routing, multimedia), faster response times, and potentially increased response rates. Jansen et al. (2007) nevertheless warn that despite 15 years of research, the realization of these benefits has been mixed. New methodologies raise problems in sampling, consistency, participant motivation, and even cost savings are not always guaranteed (Yun \& Trumbo, 2006). Advanced features may have little impact on an already well-designed survey and an electronic format alone is no guarantee of good design. Practical management often remains key: "There is no computerized substitute for a well-designed, well-supervised field work effort" (Goldstein, 2012). The implications of cost, response rate, and response bias between paper and e-surveys will now be examined.

Comparisons between pen and paper interviewing (PAPI) and computer assisted personal interviewing (CAPI) can be found in fields where lengthy structured interviews, such as household surveys, are carried out. A case study of Oxfam GB in the Philippines and Thailand details the move from PAPI to CAPI across hundreds of hour-long 
interviews. This estimates that even with relatively low labor costs for data entry ( $\$ 20$ per day), hardware costs $(\$ 300$ per device) would be recouped quickly (Tomkys \& Lombardini, 2015). The difference in response rate and costs for three identical surveys of professionals were tested, one paper/ mail based, one web based, and one using both. Total costs per response were $\$ 4.78$ paper, $\$ 0.64$ web-based, and $\$ 3.61$ mixed mode, the latter of which had the greatest response rate (Greenlaw \& Brown-Welty, 2009). A comparison of methods for a medical survey found that the total cost, adjusted for each fully completed questionnaire, ranged from $\$ 0.57$ to $\$ 1.70$ for web-based methods and $\$ 3.36$ to $\$ 4.21$ for paper-based methods. In this case, the authors state that where 200 or more responses are required, it was financially worthwhile to consider digital methods (Uhlig, Seitz, Promesberger, \& Busse, 2014).

With regard to response rates, Evans and Mathur (2005) summarized a range of articles comparing online surveys to more traditional methods. Potential weaknesses of online surveys are given as: sample representativeness, perception as junk mail, implementation cost, and low response rates. Nulty (2008) compared eight surveys where the average response rate for face-to-face was $56 \%$ while online was 33\%, commenting: "What is unknown is whether response rates to online surveys would rise to the same level if they were also conducted in a face-to-face way" (p. 303). Cronk and West (2002) provided a four-way comparison of personality test responses to take-home and in-class surveys in both paper and electronic formats. This found essentially no difference in response rate between paper and web-based in-class surveys, while both paper and web-based take-home surveys had lower response rates than their equivalents, with take-home webbased surveys performing worst overall. The personality test results did not vary across the groups, though samples were relatively small.

Response bias was deliberately tested in a UKbased study, where face-to-face interviews and online surveys were conducted with separate samples (Duffy, Smith, Terhanian, \& Bremer, 2005). Results were weighted both demographically and by propensity score matching. The unweighted online survey reported higher preferences for some political parties than in the face-to-face sample, but when weighted, the two samples were relatively close. Duffy et al. (2005) suggested these effects are related to social desirability in a face to face interview and higher levels of education and political activism among internet users. Online respondents were more likely to select neutral options for sensitive issues, suggesting that face to face situations encourage more polarized responses. A US-based study compared a convenience sample of responses collected via web survey and Amazon Mechanical Turk (MTurk) to the American National Election Studies (ANES) online probability sample (Levay, Freese, \& Druckman, 2016). Although the online responses varied across socioeconomic and political differences, once the largest variations were accounted for (in this case: age, gender, race and ethnicity, income, education, marital status, religion, ideology, and partisanship) the differences across many survey items significantly narrowed. The authors nevertheless warn that such experimental approaches do not replace observational and population-based surveys.

In terms of cost, it may be wise to estimate a break-even point when comparing paper and electronic surveys, where any benefits from reduced data entry and ease of distribution will be achieved. In terms of response rate, it is likely that in-person or proximate surveying with a somewhat "captive" audience will be significantly more effective than remote options, regardless of whether this is by paper or electronic formats. Finally, the implications for response bias will vary depending on the topic at hand but it seems likely that both the influence of an interviewer and the self-selecting nature of web survey respondents will both be worth consideration. Weighting online samples to better reflect more known demographics is possible, though it is likely an unfamiliar technique for many. There will be other significant reasons for considering pre, during, and postevent surveying, which will likely further affect choices of methodology and technology.

\section{Event Technology}

Increased smartphone ownership is a potentially valuable avenue for electronic survey distribution, whether users are in proximity to the event or not. Hyperlinks, QR codes, NFC, or Bluetooth functions 
could all potentially be used to encourage participation. In $2018,78 \%$ of UK adults and $95 \%$ of $16-24$ year olds owned a smartphone, while smartphones also overtook laptops as the most important device for connecting to the internet (Office of Communications, 2018). A working paper from NCRM explored the diversity of devices being used to participate in a number of online surveys and underlying demographic factors (Masolvskaya, Durrant, Smith, Hanson, \& Villar, 2017). In the mid-2000s, researchers often did not accommodate or actively discouraged the use of mobiles, while today it should be assumed that web surveys will be accessed on a range of devices. Those who were younger, female, employed, with higher household income, and in households with children were all more likely to use mobile devices over PCs. Level of education was not found to be significant. Many findings correlated with other European studies.

Events and festivals seem increasingly likely to commission mobile apps for various reasons and these may be a new avenue of collecting audience data. A survey of event professionals found that $46 \%$ had used event apps and 26\% were considering this (EventMB, 2018). Some suggest that the average amount spent on an event app was $1.2 \%$ of an events budget, though this varied depending on event size (Martin \& Luiz, 2016). Apps could have survey functions built in, but this does not appear to be a high priority for either users or developers (Luxford \& Dickinson, 2015). Providing Wi-Fi may be a further way of collecting some audience data (InTechnologyWiFi, 2015). A variety of approaches using GPS, cell towers, Bluetooth, and Wi-Fi referred to together as "location services" can be used by developers to track users to varying degrees of geographic accuracy. Bluetooth beacons are relatively cheap, low-power devices that can communicate with smartphones at short range (around $10 \mathrm{~m}$ ). A study of the Roskilde music festival used 33 Bluetooth beacons to record over 1 million points of data from 8,500 unique devices or about $6 \%$ of the audience, and mapped their movements around the site (Larsen, Sapiezynski, Stopczynski, Moerup, \& Theodorsen, 2013). This collected a unique MAC address from any device that was "discoverable" and did not require any direct audience engagement. Anonymized call detail records (CDRs) were analyzed in relation to special events in Andorra. These data, originally collected for billing purposes, could identify unique devices, times/dates of entry/exit, relative location to cell towers and attractions, nation of origin, and new or return visitor status. Estimated levels of disposable income were based on the brand/model of handset being used (Leng et al., 2016).

Despite the prevalence of smartphones, there are factors fragmenting this group, particularly in an event environment. Increasing prevalence of devicecharging services at outdoor events and festivals is evidence that both audiences and organizers value smartphone usage, for various purposes (EE Press Office, 2015). Although the most recent Bluetooth standard (BLE or Bluetooth 4.0) is more energy efficient than earlier versions, users may still disable one or all location services for power saving or privacy reasons ("Bluetooth Smart Beacons," 2014). Two agencies working in this area have estimated that $60 \%$ (Coombs, 2017) to $80 \%$ (Verbree, 2016) of users in the UK, North America, and Australia have location services enabled. Alternatively, some event audiences may avoid risks by bringing cheaper "dumbphones" without major app stores, GPS, or Bluetooth (Gardner, 2013). Hardware manufacturers may be more likely to enable privacy features by default (Matte \& Cunche, 2017).

Legislation like the EU General Data Protection Regulation (GDPR) is increasing awareness and potential liabilities for many data processors and controllers. Many event technologies will, in theory, face higher levels of scrutiny, though awareness of user rights and relevant practices in software design arguably remain limited. The degree to which different types of survey could constitute the collection of personally identifying data is up for debate, but the situation nevertheless highlights the ease at which nonspecialists can adopt technologies without evaluating potential risks. There are too many variables to cover, but briefly, the EU-US Privacy Shield is often viewed as a way for many USbased services to be deemed "GDPR compatible." Few will be unaware of the Facebook-Cambridge Analytica scandal, yet both were, at the time, selfcertified to Privacy Shield standards. This case has been at the forefront of further calls for reform, despite low levels of formal complaints made so far under the existing scheme (Skadden, Arps, Slate, Meagher, \& Flom LLP, 2018). The European Court 
of Justice has ruled that organizations using technologies are jointly (though not equally) responsible for data processing, even when the "client" organization only has access to an excerpt of partial, anonymized data (Baxter, 2018). Given the frequently interlinked nature of data collection, one flaw could lead to further compromises and/or legal challenges, across a single organization or a collaborative network.

The sheer volume and availability of raw data relating to event stakeholders - particularly audiences - has increased, which is broadly welcomed by researchers. e-Surveys and other methods of data collection hold the promise of cheaper, faster, and better-quality data than traditional surveys. Nevertheless, there are significantly increased technical complexities, demographic and response bias effects that need to be taken into account. There are few, if any, events-related pieces of research that directly compare results of traditional surveys with technological approaches; whether more "active" (a web survey or an app) or "passive" (location tracking or geo-demographic segmentation). Positively, there is increased potential for mixed methods and triangulation from numerous data sources. Negatively, it may be that e-surveys and other technological methods are adopted primarily in the hopes of cost savings and even this is not always guaranteed.

\section{Methodology}

\section{Developing a Criterion}

A purposive sampling approach was adopted to establish the currency of survey-based event management research. This allowed the creation of criteria for selecting specific journals to interrogate, to identify specific articles to review, and to ascertain the methods they employed (Skinner, Edwards, \& Corbett, 2014). This approach allowed for a subset of articles to be selected from an initially larger sample (Babbie, 2013). Two sets of criteria are explained below: how journals were selected and how they were sampled.

\section{Selecting the Journals}

The first stage of selection was to engage with a journal list that would ensure research quality and impact of the articles for review. There are numerous listings available, such as the Erasmus Research Institute of Management and Australian Business Deans Council. However, it is important to note that these journal listings contain certain flaws. For example, although these lists attempt to "convey an impression of impartiality and objectivity" (Willmott, 2011, p. 430), Hall (2011) noted that nascent areas of research and certain methodologies can be marginalized within these journal lists.

To counter some of these criticisms, The UK Association of Business Schools list (ABS Journal Quality Guide) was selected for three main reasons. Firstly, the ABS list is an internationally accepted guide that acknowledges diversity and difference in research (Rowlinson, Harvey, Kelly, \& Morris, 2011). Secondly, the ABS list provides a more transparent approach to its selection of journals, including a detailed overview of how these are selected for inclusion (Willmott, 2011). Finally, it breaks down journals into subfields, informing the researcher of an appropriate selection of journals (Kelly, Harvey, Morris, \& Rowlinson, 2013).

Event management is now a well-established field of research. When reviewing the ABS listings, five journals were identified as being dedicated event journals (see Table 1). This is heartening

Table 1

Association of Business Schools (ABS) Ranking of Event Management Journals

\begin{tabular}{lcccr}
\hline Journal & ABS 2015 & ABS 2018 & Inception & No. of Articles Analyzed \\
\hline Event Management (EM) & $2^{*}$ & $2^{*}$ & 2000 & 145 \\
Intl. Journal of Event and Festival Management (IJEFM) & $1^{*}$ & $1^{*}$ & 2010 & 44 \\
Journal of Convention \& Event Tourism (JCET) & $1^{*}$ & $1^{*}$ & 2004 & 55 \\
Journal of Sport \& Tourism (JST) & $1^{*}$ & $1^{*}$ & 1993 & 42 \\
Total & & & & 286 \\
\hline
\end{tabular}


to see as previous methodological research by Crowther et al. (2015) identified a lack of coherency in relation to the ABS criteria and event management journals. Of the five initially selected, the Journal of Policy Research in Tourism, Leisure and Events (JPRTLE) was later excluded as it only yielded four articles under the criteria.

\section{Sampling the Articles}

In order to build a sample of specific articles from each journal, a set of criteria were developed before reviewing began. Firstly, only those articles that analyzed a specific, singular, event phenomena were selected. This excluded research based on industry expert reflections, series of events, venues, or conceptual pieces. This would provide a more representative view of empirical research that used contemporary and historical survey methods to generate primary data.

Citation analysis was used to identify articles that have resonated within the research community. Google Scholar was employed because coverage is more complete than comparable tools such as Scopus and Web of Science, specifically in the related fields of social science and business and administration (Harzing \& Van der Wal, 2008). Only those articles that received at least one citation were selected for the sample, as indicators of: the "impactfulness" of the research (Sarli, Dubinsky, \& Holmes, 2010), which articles are influencing the current research agenda (Moed, 2009), and to some degree helping to quantify the overall "scientific quality of the paper" (Nightingale \& Marshall, 2012, p. 60). Finally, to quantify which articles made use of a survey method textual analysis was used. This allowed analysis to "focus on just a selected few features of texts" (Fairclough, 2003, p. 6).
In total, this created an initial sample size of 303 articles, which reduced to 286 . This nevertheless exceeds the previous review by Crowther et al. (2015) (165 articles). Once articles were identified, information was collated regarding the research and survey methodology. The events themselves were classified according to Getz's (2007) event typology. Secondly, information about the sampling technique was gathered. Thirdly, whether single or multiple methods were used. Fourthly, whether the survey was conducted proximately (face-to-face) or remotely. Fifthly, what type of survey was utilized in the research and whether a software package was stated. Finally, when the survey was conducted in relation to the event, and which stakeholders were targeted.

\section{Findings}

This section presents key findings of the systematic content analysis. Table 2 compares Event Management (145 articles) and 141 articles in "other event journals" (IJEFM, JCET, \& JST). This initial analysis presents a relatively unvarying picture throughout the journals reviewed, with some key differences. Eighty-six percent of all articles reviewed used a single survey as the sole method, with only $14 \%$ using a survey and at least one other method. Thirty-one percent of those using multiple methods used additional surveys, often at different timings or in different formats. This is consistent across individual journals and within the collapsed category. Only IJEFM was below this average, though it only contributed $15 \%$ of the total articles.

Although Table 2 establishes the dominance of the single survey method, Table 3 begins to examine the detail of the survey methods used. Three

Table 2

Overview of the Journal Articles Reviewed

\begin{tabular}{lcccccccc}
\hline & & & & & \multicolumn{3}{c}{ Additional Method Employed } \\
\cline { 5 - 9 } Journal & Articles & $\begin{array}{c}\text { Single } \\
\text { Survey }\end{array}$ & $\begin{array}{c}\text { Multiple } \\
\text { Methods }\end{array}$ & Interviews & $\begin{array}{c}\text { Focus } \\
\text { Group }\end{array}$ & $\begin{array}{c}\text { Multiple } \\
\text { Surveys }\end{array}$ & Diaries & Observations \\
\hline Event Management & 145 & $86 \%$ & $14 \%$ & $41 \%$ & $18 \%$ & $33 \%$ & $4 \%$ & $4 \%$ \\
Other event journals & 141 & $87 \%$ & $13 \%$ & $45 \%$ & $17 \%$ & $33 \%$ & - & $5 \%$ \\
Total & 286 & $86 \%$ & $14 \%$ & $44 \%$ & $18 \%$ & $31 \%$ & $2 \%$ & $5 \%$ \\
\hline
\end{tabular}


Table 3

Methods Utilized by Journals

\begin{tabular}{|c|c|c|c|c|c|c|c|c|c|}
\hline \multirow[b]{2}{*}{ Journal } & \multicolumn{2}{|c|}{ Proximity } & \multicolumn{5}{|c|}{ Format } & \multicolumn{2}{|c|}{ Mediation } \\
\hline & Proximate & Remote & Paper Based & On-line & E-mail & Postal & Phone & Self-Completion & Interviewer Led \\
\hline Event Management & $67 \%$ & $33 \%$ & $66 \%$ & $18 \%$ & $5 \%$ & $11 \%$ & $1 \%$ & $91 \%$ & $9 \%$ \\
\hline Other event journals & $66 \%$ & $34 \%$ & $64 \%$ & $23 \%$ & $3 \%$ & $9 \%$ & $1 \%$ & $97 \%$ & $3 \%$ \\
\hline Total & $67 \%$ & $33 \%$ & $65 \%$ & $21 \%$ & $4 \%$ & $10 \%$ & $1 \%$ & $94 \%$ & $6 \%$ \\
\hline
\end{tabular}

key, independent, dimensions of surveys can be observed. We have termed these: Proximity (proximate to the event or remote), Format (paper-based and others), and Mediation (interviewer led or self-completion). The most important aspect established is the tradition of paper-based surveys and the likely impact on sampling time and proximity. The largest sea change over time has been the increase in electronic (online and e-mail) methods. These methods only began to appear from 2009 but have since grown to $25 \%$ of all articles, or $31 \%$ of articles from 2009 onwards. Importantly, of the 60 articles using electronic methods, nearly two thirds (37) did not report the software being used.

Among journals, JST provided the only counterflow to wider trends, with $74 \%$ of articles being proximate compared to the overall average of $67 \%$. JCET had a slightly higher than average usage of remote surveys (40\%). Sports events (JST) may emphasize reaching stakeholders "there and then," while business events (JCET) may have the necessary contact information for remote, probably postevent engagement.

Table 4 examines when surveys were conducted in relation to the event and the type of event. Of all surveys used, $10 \%$ were carried out before the

Table 4

Timing of Survey by Type of Event

\begin{tabular}{lrrrr}
\hline Type of Event & Times Used & Before & During & After \\
\hline Business & 13 & $0 \%$ & $37 \%$ & $63 \%$ \\
Cultural & 17 & $0 \%$ & $76 \%$ & $24 \%$ \\
Festival \& celebrations & 58 & $5 \%$ & $66 \%$ & $29 \%$ \\
Food & 12 & $0 \%$ & $58 \%$ & $42 \%$ \\
Music & 34 & $18 \%$ & $38 \%$ & $44 \%$ \\
MICE & 19 & $0 \%$ & $37 \%$ & $63 \%$ \\
Sport & 129 & $16 \%$ & $44 \%$ & $40 \%$ \\
Tourism & 9 & $11 \%$ & $33 \%$ & $56 \%$ \\
Total & 291 & $10 \%$ & $49 \%$ & $41 \%$ \\
\hline
\end{tabular}

event, $49 \%$ during the event, and $41 \%$ after the event. Preevent surveys often examined preconceptions or anticipated impacts. Music and sport events contributed the highest amount of preevent surveys ( 6 and 20 articles, respectively), covering events such as the Olympic Games, the FIFA World Cup, and concerts by $\mathrm{U} 2$.

Business (including MICE) events had no preevent data collection and the highest percentage of postevent scores, both $63 \%$. This may relate to the relative ease of contacting respondents but also that postevent economic impact or business development were key themes. A further observation is that cultural events had no preevent collection but the highest during-event data collection (76\%), presumably reflecting practicalities but possibly also the value placed on immediate experiences.

Table 5 shows that "paper-based survey" is often a synonym for sampling taking place during events (68\%), while electronic methods are more commonly for postevent sampling. Eighty-two percent of all online surveys were employed postevent and these accounted for $41 \%$ of all postevent data collection.

The timescale of sampling employed by the articles can be seen in Table 6. The use of single and multiple methods is fairly consistent across sampling timescales although as the length of data

Table 5

Timing of Survey by Format of Survey

\begin{tabular}{lrrrr}
\hline Format of Survey & Times Used & Before & During & After \\
\hline Paper based & 196 & $12 \%$ & $68 \%$ & $20 \%$ \\
Online & 61 & $7 \%$ & $10 \%$ & $84 \%$ \\
E-mail & 11 & $0 \%$ & $18 \%$ & $82 \%$ \\
Postal & 31 & $16 \%$ & $16 \%$ & $68 \%$ \\
Phone survey & 3 & $0 \%$ & $33 \%$ & $67 \%$ \\
Total & 302 & $11 \%$ & $49 \%$ & $40 \%$ \\
\hline
\end{tabular}


Table 6

Methods Utilized by Timescale

\begin{tabular}{|c|c|c|c|c|c|c|c|c|c|c|}
\hline \multirow[b]{2}{*}{ Timescale } & \multirow[b]{2}{*}{ Articles } & \multicolumn{2}{|c|}{ Methodology } & \multicolumn{2}{|c|}{ Proximity } & \multicolumn{5}{|c|}{ Delivery Format } \\
\hline & & $\begin{array}{l}\text { Single } \\
\text { Survey }\end{array}$ & $\begin{array}{l}\text { Multiple } \\
\text { Methods }\end{array}$ & Proximate & Remote & Paper Based & Online & E-mail & Postal & Phone \\
\hline 1 day & 21 & $11 \%$ & $7 \%$ & $14 \%$ & $2 \%$ & $13 \%$ & $0 \%$ & $0 \%$ & $7 \%$ & $0 \%$ \\
\hline 2 days & 44 & $23 \%$ & $21 \%$ & $27 \%$ & $12 \%$ & $27 \%$ & $4 \%$ & $0 \%$ & $15 \%$ & $0 \%$ \\
\hline 1 week & 51 & $27 \%$ & $29 \%$ & $30 \%$ & $14 \%$ & $32 \%$ & $9 \%$ & $50 \%$ & $7 \%$ & $0 \%$ \\
\hline 4 weeks & 43 & $23 \%$ & $21 \%$ & $19 \%$ & $35 \%$ & $19 \%$ & $57 \%$ & $0 \%$ & $0 \%$ & $100 \%$ \\
\hline +4 weeks & 31 & $16 \%$ & $22 \%$ & $10 \%$ & $37 \%$ & $9 \%$ & $30 \%$ & $50 \%$ & $71 \%$ & $0 \%$ \\
\hline
\end{tabular}

collection increases, some trends emerge. When data collection lasts more than 1 week, remote research begins to increase. This was $35 \%$ of the articles up to 4 weeks (43 articles), and $52 \%$ of those above 4 weeks ( 31 articles). Online methods became more apparent as the length of data collection increases, with $87 \%$ of the online methods used for data collection that lasts longer than 1 week. A table is not included here, but it is also useful to note the specific sampling methods were also examined, with the most frequent three stated being random $(23 \%)$, purposive $(23 \%)$, and convenience $(22 \%)$. Importantly, only $75 \%$, or 216 articles, explicitly stated the sampling methodology they employed.

Finally, Table 7 examines different methods being utilized with different stakeholder groups. Face to face accounted for a total of $66 \%$ of the studies, while remote accounted for $34 \%$. Remote saw a higher usage in relations to managers $(69 \%)$, volunteers $(59 \%)$, and athletes $(42 \%)$, probably in situations where researchers have easy access to contact information. This is further confirmed by the above average use of online methods for these groups. Audience engagement was primarily through proximate $(80 \%)$, paper-based $(75 \%)$ methods and presumably reflects entry-exit surveys, roaming researchers with clipboards or more passive feedback/comment box approaches.

\section{Discussion}

To highlight some of the implications of using different survey methods, articles in the sample that used multiple surveys were further examined. Forty articles used multiple methods, and of those 8 used multiple surveys. Although none of these deliberately set out to examine methodological effects, they still provide insight to issues more specific to the events field.

Firstly, electronic methods are frequently used among managers but their ease of distribution could also make them easy to ignore. Three studies using multimode approaches to reach event managers had between $4 \%-13 \%$ response rates with e-mail, all lower than the other modes used (Gibson \& Connell, 2015; Pasanen \& Konu, 2016; Robertson et al., 2009). Secondly, pre- and postevent surveys are sometimes used, both out of deliberate research design and convenience (Elstad, 2003). Satisfaction-type responses were not significantly

Table 7

Methods Utilized by Stakeholder Type

\begin{tabular}{|c|c|c|c|c|c|c|c|c|c|c|c|}
\hline \multirow[b]{2}{*}{ Stakeholder } & \multirow[b]{2}{*}{ Articles } & \multicolumn{3}{|c|}{ Timing of Survey } & \multicolumn{2}{|c|}{ Proximity } & \multicolumn{5}{|c|}{ Delivery Format } \\
\hline & & Before & During & After & Proximate & Remote & Paper Based & Online & E-mail & Postal & Phone \\
\hline Athletes & 30 & $6 \%$ & $50 \%$ & $44 \%$ & $58 \%$ & $42 \%$ & $51 \%$ & $37 \%$ & $0 \%$ & $6 \%$ & $0 \%$ \\
\hline Audience & 153 & $10 \%$ & $64 \%$ & $26 \%$ & $80 \%$ & $20 \%$ & $75 \%$ & $8 \%$ & $1 \%$ & $7 \%$ & $0 \%$ \\
\hline Managers & 35 & $6 \%$ & $34 \%$ & $60 \%$ & $31 \%$ & $69 \%$ & $23 \%$ & $29 \%$ & $10 \%$ & $13 \%$ & $2 \%$ \\
\hline Nonparticipants & 46 & $15 \%$ & $27 \%$ & $58 \%$ & $67 \%$ & $33 \%$ & $49 \%$ & $15 \%$ & $2 \%$ & $15 \%$ & $4 \%$ \\
\hline Volunteers & 22 & $17 \%$ & $21 \%$ & $63 \%$ & $41 \%$ & $59 \%$ & $30 \%$ & $41 \%$ & $11 \%$ & $4 \%$ & $0 \%$ \\
\hline
\end{tabular}


affected in one case where "paper-during" and "online-post" surveys were used, though potential impact on representativeness (national origin of athletes in this case) was not examined (Macintosh \& Nicol, 2012). In one pre- and postevent survey, demographic representativeness was examined and controlled for, through careful sampling (Heere et al., 2016). Finally, time of surveying and effects on expenditure is a particular area of interest. Some suggest that higher spending is reported during the event (Case, Dey, Phang, \& Schwanz, 2013), while others have found the reverse (Wicker, Hallmann, \& Zhang, 2012), although in the latter case the further implications of electronic/paper and different types of respondents were not specifically examined. Two further articles, outside the original literature review, and linked by an author, have found both higher spending during (Case, Tanujit, Gillespie, Luckett, \& Pawlosky, 2017) and after some events (Case \& Yang, 2009). This brief summary further highlights the relatively confusing view researchers may find when looking for guidance on the impact of different survey methods, likely leading to reliance on whichever appears the most convenient or familiar.

If the usage of surveys within academic research is substantial, it is also familiar to events evaluators and practitioners. This work does not often appear in journals but is influenced by, and influential towards, the academy. Some have critiqued "external-between" research that emerges in collaboration with, and blurs the lines between, the academy and commercial consultancies (Oman \& Taylor, 2018). There have been long-standing concerns in the cultural sector around advocacydriven evidence (Crossick \& Kaszynska, 2016). Nevertheless, Getz and Page (2016) suggested that institutions, professional events associations, and local event groups may be key actors in helping to address the "chronic gap between academics and practitioners" (p. 350). Although cultural sector practitioners in the UK were positive about even short-term academic collaboration, they could also find the process "difficult to understand, slow in delivery and expensive" (Kasynska, 2018, p. 14).

Umbrella bodies and associations were often delegated the responsibility for research and information sharing. Funding bodies, networks, and other sector-spanning organizations have developed as key information hubs. The Audience Agency (TAA) in the UK supports over 600 arts, culture, and heritage organizations who contribute data to its national audience data tool: "Audience Finder." DataArts may be considered a similar initiative in the US. Around 280,000 standardized surveys have been completed to date. The survey can be completed "face-to-face" or online and it can be seen in Table 8 that different organizations use different methods.

Venues with higher dwell times evidently find it more feasible to carry out face-to-face (presumably proximate) surveys, whereas online (presumably remote) becomes more important when audiences arrive and depart rapidly. Festivals/Outdoor Arts organizations have a mix of both, though the exact format of events (indoor, outdoor, number of days, etc.) this encompasses is unknown. It was not possible to distinguish the data further, into paperbased or electronic methods.

The organizations using Audience Finder are likely to be more established and in receipt of public funding than a great number of other events, both "cultural" and otherwise (sports, business, etc.). Correspondence with an ex coordinator of the British Arts Festivals Association confirmed many voluntary-led organizations struggled to have the resources to use even relatively simple methods like surveys to their fullest and may be more likely to rely on relatively limited information provided by a box-office platform, segmentation, or social media. Free to attend or unticketed events had an even larger challenge. Where surveys were used, they were predominately paper-based and completed during the event (K. Hart, personal communication, July 17, 2018).

Although many organizations can see the value in taking a more joined-up approach to survey

Table 8

Audience Agency 2016/2017 Survey Methodology by Organization Type

\begin{tabular}{lcr}
\hline Organization & Face-to-Face & Online \\
\hline Museum/heritage & $97 \%$ & $3 \%$ \\
Festival/outdoor arts & $67 \%$ & $33 \%$ \\
Performing arts/concert hall & $20 \%$ & $80 \%$ \\
Average & $70 \%$ & $30 \%$ \\
\hline
\end{tabular}

Note. Source: K. Cudworth, personal communication, January 16, 2018. 
methods across their sectors, there is a balance to be struck between potentially counterproductive one size fits all approaches, and those that respect the unique circumstances and interests of individual events. Few practitioners or academics are entirely unfamiliar with some of the methodological considerations for appropriate survey use, even if this is only as an occasional survey respondent themselves. However, this familiarity arguably masks a lack of in-depth consideration, leading to ineffective, inefficient practices, reinventing the wheel, and "glossing over" the detail, biases, and implications of an expanding, diverse array of survey methods.

\section{Conclusions}

Our conclusions emerge at the intersection of three trends. Firstly, electronic survey methods are becoming more prevalent and diverse, necessitating greater technical understanding and experimentation. Secondly, some of the once unique features of survey research are being challenged by data that are technological in both origin and collection, combining transactional big data and web/ social media sources. Thirdly, information and knowledge management are becoming important skills for practitioners, at least partially due to the demands of policymakers and funders.

Practitioners may turn to one of numerous software-as-a-service (SaaS) solutions to aid their day to day information management needs. These can incorporate various functions across ticketing, project management, and mobile apps. Likely the most well-known is Eventbrite, having processed more than $\$ 8$ billion in gross ticket sales since 2006 (Green, 2018). A web search at the time of writing returned over 400 unique results for "Event Management Software" (Capterra Inc., n.d.). Event managers are not software developers and clearly many find utility in off-the-shelf solutions. The wider issue for events research is not whether a given technology is inherently flawed, it is that the data collected and methodologies involved can be hard or impossible to independently verify outside of the "walled garden" of proprietary software. Ownership of data and information is at the core of these services, and each will of course reify its own insights as the most accurate and valuable, often aiming to upsell further services, particularly those that may help reach prospective audiences. The Free Software Foundation argues that SaaS greatly exacerbates many of the problems that already exist within any proprietary software (Stallman, 2010). Ethics aside, the time-pressed manager may be more familiar with the practical downsides. Features are locked behind pricing tiers or suddenly discontinued, customization is limited, data cannot be transferred to a competing service, and so on. Legal issues around data protection also provoke concern, despite the appeal of sharing data. One artistic director described the environment around audience data as: "an arms race of protectionism" (Romer, 2015).

When data are increasingly able to be operationalized or even commoditized, we should of course question who controls the information. For one example, Arts Council England (ACE) received negative backlash over the development of the "Quality Metrics" platform (now the Impact and Insight Toolkit) through which participation and completion of standardized surveys has become a funding requirement for many organizations (Fletcher, 2015). Even if the significant concerns around quantifying artistic quality are put aside, the more practical concerns alone are worth consideration: the ongoing costs to participate, the potential for gaming the system, who the data will be owned by, accessibility to disabled users, and those with English as a second language. Others speculate that the system may ultimately be replaced by "the next big idea" before any return on investment is achieved. The invitation to tender at $£ 2.7$ million was the largest single tender ever from ACE. One director stated: "ACE seems to have been convinced by someone to spend a huge amount of money on something that could be done for very little with a set of standardized questions and a Google form." Another director gave the system an appropriately quantified rating of its own: "two out of ten" (Hill, 2017). Development costs and barriers to entry for all software will continue to lower, while digital projects in many sectors frequently fall short of expectations (Genpact Research Institute, 2015).

Some admittedly innovative technological aspects can easily overshadow the infinitely more valuable input, buy-in, and efforts of the user base themselves, who become increasingly reliant on these systems yet have little control or input to their underlying design. "Opaque" software platforms are problematic, yet 
the resulting impact on methods and research may be of deeper concern. Who decides what data counts? Is cooperation encouraged or deterred? Who owns which steps of the process? How do we suppose that data is processed into knowledge, within a model of knowledge management (Murray, 2002)? Surveys are clearly a magnet for wider policy level processes, such as those detailed above, that we could describe as "operationalized knowledge management." There is certainly further debate to be had about how policymakers use surveys to interpret and, ultimately, govern reality (Law, 2009).

We suggest that both open-source software and open-scientific practices need encouragement in the expansion of events knowledge. This is not unique to events studies and the reproducibility crisis has impacted across many established fields and respected journals (Albert, 2006; Ioannidis, 2005; Munafo et al., 2017). Given the prevalence of survey methods, we can highlight Open Data Kit (ODK) (Hartung et al., 2010) as one option, which allows for electronic, offline-capable, and open-source surveys to be deployed. ODK has also been previously identified by researchers outlining a "mass gathering data acquisition and analysis" (MaGDAA) project, to be used in events contexts, alongside other sensors based on open hardware and software (Wallis, Hutton, Brown, Challans, \& Gardner-Stephen, 2013). Mobile ethnography in its own right may be a topic of increasing interest, using surveys or otherwise (Brown \& Hutton,
2013). Finally, one survey of 750 human research ethics boards found that even though online surveys made up $94 \%$ of studies being reviewed there was poor understanding of the various benefits and drawbacks of these tools, with convenience and cost being the driving factors. Thirty-five percent indicated that they did not review privacy or security policies of commercial survey tools being used, and only one reported that they had developed their own survey tool (Buchanan \& Hvizdak, 2009).

Methods as seemingly well-worn as surveys still have significant variation and continue to develop. Even if a survey fails to reveal what it claims to about this or that stakeholder or event, it still gives insight into the perspective of its designers. Academics should be clear that transparency of methods and data are central elements of the scientific process. Practitioners should likewise support systems that respect user freedoms and do not leave them juggling multiple streams of proprietary and potentially contradictory data and analytics.

\section{Recommendations}

Emerging from our research, we propose a typology of event surveys along the following seven factors. We acknowledge that researchers are not immune to pressures of cost and convenience, but they should still fully consider and make explicit their decision making around each of these factors (Table 9).

Table 9

Typology of Event Surveys

\begin{tabular}{ll}
\hline Factor & \multicolumn{1}{c}{ Notes } \\
\hline Proximity & $\begin{array}{c}\text { Proximate or remote. Avoid using "face to face" as a synonym for "proximate" as it implies that interviewers } \\
\text { were involved, when this may not be the case. }\end{array}$ \\
Mediation & $\begin{array}{c}\text { Self-completion or interviewer-led. Did interviewers lead the whole process, were they available to clarify } \\
\text { questions, or were they not involved at all? } \\
\text { Data collected before, during, and after the event. Does timing play an important role in the research other than } \\
\text { practicality? Further detail should be included: during could be at the start or end of an event, after could be } \\
\text { immediately or months later, etc. }\end{array}$ \\
Timing & $\begin{array}{c}\text { Primarily either paper or electronic but phone and postal surveys may also be specified. Electronic should } \\
\text { include further detail on promotion, distribution and access: direct e-mail, social media, website link, tablet or } \\
\text { kiosk, etc. }\end{array}$ \\
Software & $\begin{array}{c}\text { Potentially relevant for all types of surveys, especially electronic. Any software used in the creation and dis- } \\
\text { semination of a survey, or for the analysis of results. }\end{array}$ \\
Dsually in days. Particularly for longer running events and where, if multiple waves or multiple surveys are \\
used, when each survey began and finished.
\end{tabular}


Cases where future research would be valuable are as follows. A priority is the difference between during-event paper surveys and after-event online surveys, as these seem to be the two most common approaches. The potential for surveys to contribute to longitudinal studies is also relatively clear. The potential technical benefits of e-surveys could be tested in situations where paper surveys have previously been used (e.g., with audiences, during event surveys). Preevent surveys across many types of events are rare, whether in isolation or to compare with during and/or after event surveys. The role of interviewer mediation may be of additional consideration, perhaps as part of a wider examination of other environmental influences on respondents.

Researchers could make both data collection tools and raw data more open and available for future use, particularly with regards to new analysis or the reproduction of results. A recent exploration of some best practices in data management can be found in Wilson et al. (2017). This all potentially requires greater understanding of open software and methods but this is not a unique challenge (Alsheikh-Ali, Qureshi, Al-Mallah, \& Ioannidis, 2011). Metadata and paradata are rarely investigated in events research. Compiling more information on commonly used survey designs, phrasing of questions, length, language translations, and layout might be of further value, even if standardization is not the objective.

\section{References}

Albert, K. M. (2006). Open access: Implications for scholarly publishing and medical libraries. Journal of the Medical Library Association, 94(3), 253-262.

Alsheikh-Ali, A. A., Qureshi, W., Al-Mallah, M. H., \& Ioannidis, J. P. (2011). Public availability of published research data in high-impact journals. PLOS One, 6(9), e24357. doi: https://doi.org/10.1371/journal.pone.0024357

Babbie, E. R. (2013). The basics of social research (6th ed.). Wadsworth, UK: Cengage Learning.

Baxter, M. (2018, August 7). GDPR court decisions still only a trickle: There might be a deluge yet. Retrieved from https:// gdpr.report/news/2018/08/07/gdpr-court-decisions-stillonly-a-trickle-there-might-be-a-deluge-yet/

Beissel-Durrant, G. (2004). A typology of research methods within the social sciences. Retrieved from http://eprints. ncrm.ac.uk/115/1/NCRMResearchMethodsTypology.pdf

Bhaskar, R. (1975). A realist theory of science. Leeds, UK: Leeds Books.
Bluetooth Smart Beacons for the IoT. (2014, July 31). IOT News. Retrieved from https://iotbusinessnews. com/2014/07/31/31009-bluetooth-smart-beacons-forthe-iot/

Brown, S., Getz, D., Petterson, R., \& Wallstam, W. (2015). Event evaluation: Definitions, concepts and a state of the art review. International Journal of Event and Festival Management, 6(2), 135-157.

Brown, S., \& Hutton, A. (2013). Developments in the realtime evaluation of audience behaviour at planned events. International Journal of Event and Festival Management, 4(1), 43-55.

Buchanan, E., \& Hvizdak, E. (2009). Online survey tools: Ethical and methodological concerns of human research ethics committees. Journal of Empirical Research on Human Research Ethics, 4(2), 37-48.

Burrows, R., \& Savage, M. (2014). After the crisis? Big data and the methodological challenges of empirical sociology. Big Data \& Society, 1(1), 1-6.

Capterra Inc. (n.d.). Top event management software products. Retrieved from http://www.capterra.com/eventmanagement-software/

Case, R., Dey, T., Phang, J., \& Schwanz, A. (2013). Participant spending at sporting events: An examination of survey methodologies. Journal of Convention \& Event Tourism, 14(1), 21-41.

Case, R., Tanujit, D., Gillespie, J., Luckett, D., \& Pawlosky, M. (2017). Spectator spending at a large regional volleyball tournament: An examination of survey methodologies. Athens Journal of Sport, 4(3), 181-195.

Case, R., \& Yang, W. (2009). A study to examine the differences between in person and online survey data collection methodologies. Sport Management International Journal, 5(2), 5-20.

Coombs, J. (2017, June 8). More straight goods on location: Bluetooth and location permission opt-in rates. Retrieved from https://m.rover.io/more-straight-goodson-location-bluetooth-and-location-permission-opt-inrates-cd4361acf3bc

Couper, M., \& Miller, P. (2009). Web survey methods: Introduction. Public Opinion Quarterly, 72(5), 831-835.

Cronk, B., \& West, J. (2002). Personality research on the Internet: A comparison of web-based and traditional instruments in take-home and in-class settings. Behaviour Research Methods, Instruments and Computers, 34(2), 177-180.

Crossick, G., \& Kaszynska, P. (2016). Understanding the value of arts \& culture. Swindon, UK: Arts and Humanities Research Council.

Crowther, P., Bostock, J., \& Perry, J. (2015). Review of established methods in event research. Event Management, 19(1), 93-107.

Dann, G., Nash, D., \& Pearce, P. (1988). Methodology in tourism research. Annals of Tourism Research, 15, 1-28.

Downward, P. (2005). Critical (realist) reflection on policy and management research in sport, tourism and sports tourism. European Sport Management Quarterly, 4(3), 303-320. 
Duffy, B., Smith, K., Terhanian, G., \& Bremer, J. (2005). Comparing data from online and face-to-face surveys. International Journal of Market Research, 47(6), 615-639.

Dunn, A., \& Wickham, M. (2012). The mix of research methods in the leading tourism journals: 2000-2009. Problems and Perspectives in Management, 10(1), 8-16.

EE Press Office. (2015, June 21). EE 'beefs up' connectivity at Glastonbury festival with the $4 G E E$ charging bull. Retrieved from http://newsroom.ee.co.uk/ee-beefs-upconnectivity-at-glastonbury-festival-with-the-4geecharging-bull/

Elstad, B. (2003). Continuance commitment and reasons to quit: A study of volunteers at a jazz festival. Event Management, 8(2), 99-108.

Evans, J., \& Mathur, A. (2005). The value of online surveys. Internet Research, 15(2), 195-219.

EventMB. (2018). The event app Bible 2018. Henderson, NV: Social Coup LLC.

Fairclough, N. (2003). Analysing discourse: Textual analysis for social research. London, UK: Routledge.

Falassi, A. (1987). Festival: Definition and morphology. In A. Falassi (Ed.), Time out of time: Essays on the festival (pp. 1-10). Alburquerque, NM: University of New Mexico Press.

Fletcher, R. (2015, December 2). Does more data mean more progress? Retrieved from http://www.artsprofessional.co.uk/magazine/blog/does-more-data-meanmore-progress

Fox, D., \& Gouthro, M. B. (2014). Doing events research: From theory to practice. New York, NY: Routledge.

Gardner, J. (2013, April 9). Dumb's the smart thing . . . invest in a festival phone, it lasts for 35 days and costs just £13. Retrieved from https://www.standard.co.uk/ news/techandgadgets/dumbs-the-smart-thing-invest-ina-festival-phone-it-lasts-for-35-days-and-costs-just-138565488.html

Genpact Research Institute. (2015). Putting digital to work: The lean digital way. New York, NY: Genpact.

Getz, D. (2002). Why festivals fail. Event Management, 7, 209-219.

Getz, D. (2005). Event management and event tourism. New York, NY: Cognizant Communication Corporation.

Getz, D. (2007). Event studies: Theory, research and policy for planned events. London, UK: Routledge.

Getz, D. (2010). The nature and scope of festival studies. International Journal of Event Management Research, $5(1), 1-47$.

Getz, D. (2018). Event evaluation: Theory and methods for event management and tourism. Oxford, UK: Goodfellow.

Getz, D., \& Page, S. J. (2016). Event studies: Theory, research and policy for planned events (3rd ed.). New York, NY: Routledge.

Gibson, C., \& Connell, J. (2015). The role of festivals in drought-affected Australian communities. Event Management, 19(4), 445-459.

Goldstein, M. (2012, May 25). Paper or plastic? Part II: Approaching the survey revolution with caution. Retrieved from http://blogs.worldbank.org/ impactevaluations/paper-or-plastic-part-ii-approachingthe-survey-revolution-with-caution

Green, A. (2018, May 12). Eventbrite may soon file for an initial public offering, report says. Retrieved from https:// www.bizjournals.com/sanfrancisco/news/2018/04/12/sfeventbrite-file-ipo-ticketing-platform.html

Greenlaw, C., \& Brown-Welty, S. (2009). A comparison of web-based and paper-based survey methods. Evaluation Review, 33(5), 464-480.

Hall, C. M. (2011). Publish and perish? Bibliometric analysis, journal ranking and the assessment of research quality in tourism. Tourism Management, 31(1), 16-27.

Hartung, C., Anokwa, Y., Brunette, W., Lerer, A., Tseng, C., \& Borriello, G. (2010). Open data kit: Tools to build information services for developing regions. Retrieved from http://www.nixdell.com/classes/Tech-for-the-under served/Hartung.pdf

Harzing, A., \& Van der Wal, R. (2008). Google scholar as a new source for citation analysis. Ethics in Science and Environmental Politics, 8(1), 61-73.

Heere, B., Walker, M., Gibson, H., Thapa, B., Geldenhuys, S., \& Coetzee, W. (2016). Ethnic identity over national identity: An alternative approach to measure the effect of the World Cup on social cohesion. Journal of Sport and Tourism, 20(1), 41-56.

Hill, L. (2017, February 24). Arts council earmarks $£ 2.7 \mathrm{~m}$ for quality metrics roll-out. Retrieved from https://www. artsprofessional.co.uk/news/arts-council-earmarksps 27 m-quality-metrics-roll-out

InTechnologyWiFi. (2015, July 22). Latitude Festival 2015: Free WiFi helps thousands keep in the know. Retrieved from http://www.intechnologywifi.com/blog/latitude-festival2015-free-wifi-helps-thousands-keep-in-the-know/

Ioannidis, J. P. (2005). Why most published research findings are false. PLoS Medicine, 2(8), e124. doi: https:// doi.org/10.1371/journal.pmed.0020124

Jansen, K., Corley, K., \& Jansen, B. (2007). Chapter 1: E-survey methodology. In R. Reynolds, R. Woods, \& J. Baker (Eds.), Handbook of research on electronic surveys and measurements (pp. 1-8). Hershey, PA: Idea Group Reference.

Kasynska, P. (2018). Cultural value scoping project. London, UK: Kings College London.

Kelly, A., Harvey, C., Morris, H., \& Rowlinson, M. (2013). Accounting journals and the ABS guide: A review of evidence and inference. Management \& Organizational History, 8(4), 415-431.

Larsen, J. E., Sapiezynski, P., Stopczynski, A., Moerup, M., $\&$ Theodorsen, R. (2013). Crowds, bluetooth and rock- $n$ roll. Understanding music festival participant behavior. Retrieved from https://arxiv.org/abs/1306.3133

Law, J. (2009). Seeing like a survey. Cultural Sociology, 3(2), 239-256.

Leng, Y., Noriega, A., Pentland, A. S., Winder, I., Lutz, N., \& Alonso, L. (2016). Analysis of tourism dynamics and special events through mobile phone metadata. New York, NY: Proceedings of Data for Good Exchange (D4GX). 
Levay, K. E., Freese, J., \& Druckman, J. N. (2016). The demographic and political composition of mechanical turk samples. SAGE Open, 6(1). doi: https://doi. org $/ 10.1177 / 2158244016636433$

Lu, J., \& Nepal, S. K. (2009). Sustainable tourism research: An analysis of papers published in the Journal of Sustainable Tourism. Journal of Sustainable Tourism, 17(1), $5-16$.

Luff, R., Byatt, D., \& Martin, D. (2015). Review of the typology of research methods within the social sciences. NCRM Report, National Centre for Research Methods, Southampton, UK.

Luxford, A., \& Dickinson, J. E. (2015). The role of mobile applications in the consumer experience at music festivals. Event Management, 19, 33-46.

Macintosh, E., \& Nicol, L. (2012). Athletes' event experiences of the XIX Commonwealth Games in Delhi, India. International Journal of Event and Festival Management, 3(1), 12-29.

Marsh, C. (1979). Problems with surveys: Method or epistemology? Sociology, 13(2), 293-305.

Martin, V., \& Luiz, C. (2016). Technology and events: How to create engaging events. Oxford, UK: Goodfellow Publishers.

Masolvskaya, O., Durrant, G., Smith, P. W., Hanson, T., \& Villar, A. (2017). Mixed-device online surveys in the UK (National Centre for Research Methods working paper). Retrieved from http://eprints.ncrm.ac.uk/4022/1/ Mixed device\%20surveys UK.pdf

Matte, C., \& Cunche, M. (2017). Spread of MAC address randomization studies using locally administered MAC addresses use historic. Grenoble, France: Institut National de Recherche en Informatique et Automatique.

Moed, H. F. (2009). New developments in the use of citation analysis in research evaluation. Archivum immunologiae et therapiae experimentalis, 57(1). doi: https://doi. org/10.1007/s00005-009-0001-5

Munafo, M. R., Nosek, B. A., Bishop, D. V., Button, K. S., Chambers, C. D., Percie du Sert, N., \& Ioannidis, J. P. (2017). A manifesto for reproducible science. Nature Human Behaviour, 1(21).

Murray, P. (2002). Knowledge management as a sustained competitive advantage. Journal of Business Research, 94, 320-334.

Nightingale, J. M., \& Marshall, G. (2012). Citation analysis as a measure of article quality, journal influence and individual researcher performance. Radiography, 18(2), 60-67.

Nulty, D. (2008). The adequacy of response rates to online and paper surveys: What can be done? Assessment \& Evaluation in Higher Education, 33(3), 301-314.

Office of Communications. (2018). The communications market report. London, UK: Author.

Olson, W. (2004). Triangulation in social research: Qualitative and quantitative methods can really be mixed. In M. Haralambos \& M. Holborn (Eds.), Developments in sociology (pp. 103-118). Ormskirk, UK: Causeway Press Ltd.
Oman, S., \& Taylor, M. (2018). Subjective well-being in cultural advocacy: A politics of research between the market and the academy. Journal of Cultural Economy, 11(3), 225-243.

Park, K., \& Park, S. B. (2016). Topic trend of event management research. Event Management, 20, 109-115.

Pasanen, K., \& Konu, H. (2016). Use of social media for new service development by Finnish event and festival organizers. Event Management, 20(3), 313-325.

Payne, G. (2014). Surveys, statisticians and sociology: A history of (a lack of) quantitative methods. Enhancing Learning in the Social Sciences, 6(2), 74-89.

Robertson, M., Rogers, P., \& Leask, A. (2009). Progressing socio-cultural impact evaluation for festivals. Journal of Policy Research in Tourism, Leisure and Events, 1(2), 156-169.

Romer, M. (2015, October 1). Whose data is it anyway? Retrieved from http://www.artsprofessional.co.uk/ magazine/article/whose-data-it-anyway

Rowlinson, M., Harvey, C., Kelly, A., \& Morris, H. (2011). The use and abuse of journal quality lists. Organization, 18(4), 443-446.

Sarli, C. C., Dubinsky, E. K., \& Holmes, K. L. (2010). Beyond citation analysis: A model for assessment of research impact. Journal of the Medical Library Association, 98(1), 17-23.

Savage, M., \& Burrows, R. (2007). The coming crisis of empirical sociology. Sociology, 41(5), 885-899.

Sayer, A. (2000). Realism and social science. London, UK: Sage Publications Ltd.

Skadden, Arps, Slate, Meagher, \& Flom LLP. (2018). Privacy and cybersecurity update: November 2018. Retrieved from https:/www.skadden.com/insights/publications/2018/11/ privacy-cybersecurity-update-november-2018

Skinner, J., Edwards, A., \& Corbett, B. (2014). Research methods for sport management. London, UK: Routledge.

Stallman, R. (2010, March 18). Who does that server really serve? Retrieved from http://bostonreview.net/richardstallman-free-software-DRM

Tomkys, E., \& Lombardini, S. (2015). Going digital: Using digital technology to conduct Oxfam's effectiveness reviews. Oxford, UK: Oxfam GB

Uhlig, C. E., Seitz, B., Eter, N., Promesberger, J., \& Busse, H. (2014). Efficiencies of internet-based digital and paperbased scientific surveys and the estimated costs and time for different-sized cohorts. PLOS One, 9(10), e108441. doi: https://doi.org/10.1371/journal.pone.0108441

Veal, A. J., \& Burton, C. (2014). Research methods for arts and event management. Harlow, UK: Pearson.

Verbree, M. (2016, April2 19). Localz survey results: $80 \%$ of smartphone users enable location services. Retrieved from https://blog.localz.com/localz-surveyresults-80-percent-of-smartphone-users-enable-locationservices

Wallis, C., Hutton, A., Brown, S., Challans, R., \& GardnerStephen, P. (2013). Distributed sensor logging: As easy as a mesh of yoyos. International Journal of Communications, Network and System Sciences, 6(6), 309-315. 
Wicker, P., Hallmann, K., \& Zhang, J. (2012). What is influencing consumer expenditure and intention to revisit? An investigation of marathon events. Journal of Sport \& Tourism, 17(3), 165-182.

Willmott, H. (2011). Journal list fetishism and the perversion of scholarship: Reactivity and the ABS list. Organization, 18(4), 429-442.
Wilson, G., Bryan, J., Cranston, K., Kitzes, J., Nederbragt, L., \& Teal, T. K. (2017). Good enough practices in scientific computing. PLoS Computational Biology, 13(6), 1005510. doi: https://doi.org/10.1371/journal.pcbi.1005510

Yun, G. W., \& Trumbo, C. W. (2006). Comparative response to a survey executed by post, e-mail, \& web form. Journal of Computer-Mediated Communication, 6(1). 
